\title{
CONTROLE DA ANTRACNOSE NA PÓS-COLHEITA DE BANANAS-'PRATA' COM PRODUTOS ALTERNATIVOS AOS AGROTÓXICOS CONVENCIONAIS ${ }^{1}$
}

\author{
RICARDO JOSÉ ZIMMERMANN DE NEGREIROS², LUIZ CARLOS CHAMHUM SALOMÃO 3 \\ OLINTO LIPARINI PEREIRA ${ }^{4}$, PAULO ROBERTO CECON ${ }^{5}$, DALMO LOPES DE SIQUEIRA ${ }^{6}$
}

RESUMO - Produtos alternativos aos agrotóxicos convencionais foram avaliados no controle da antracnose causada por Colletotrichum musae em pós-colheita de bananas 'Prata' [Musa spp. (AAB)]. Foram utilizados buquês com três frutos, com diâmetro médio de $32 \mathrm{~mm}$ a $36 \mathrm{~mm}$, no estádio pré-climatérico, com coloração de casca totalmente verde. Os frutos foram pulverizados com uma suspensão de conídios de C. musae, na concentração de $2,5 \times 10^{5}$ conídios $/ \mathrm{mL}$ e mantidos em câmara úmida a $25^{\circ} \mathrm{C}$, por 24 horas. Após esse período, foram pulverizados com as caldas dos produtos alternativos extrato cítrico 'Biogermex', óleo de nim 'Organic Neem'e óleo de alho 'Probinatu', na concentração de 10,0 mL/L, óleo de pimenta-longa e óleo de cravo-daíndia na concentração de $5,0 \mathrm{~mL} / \mathrm{L}$ e quitosana na concentração de $10,0 \mathrm{mg} / \mathrm{mL}$, além do fungicida Tecto ${ }^{\circ}$ SC (tiabendazol) na concentração de $0,65 \mathrm{~mL} / \mathrm{L}$. Água destilada foi utilizada como tratamento-testemunha. Os frutos tratados com quitosana, óleo de nim e óleo de alho tiveram a severidade da doença reduzida. O óleo de alho foi o produto mais eficiente, com redução também da incidência da doença. A qualidade dos frutos não foi depreciada por nenhum dos tratamentos alternativos nas concentrações utilizadas.

Termos para indexação: qualidade pós-colheita, Colletotrichum musae, fungos fitopatogênicos, óleos e extratos vegetais.

\section{POSTHARVEST CONTROL OF ANTRACNOSE IN 'PRATA' BANANAS WITH ALTERNATIVES PRODUCTS TO CONVENTIONAL PESTICIDES}

\begin{abstract}
Alternatives products to conventional pesticides in the control of anthracnose caused by Colletotrichum musae after harvest of 'Prata' banana [Musa spp. (AAB)] were evaluated. Fruits with an average diameter of 32-36 mm were selected at the pre-climacteric stage, with a peel color index of 1 (totally green peel). Hands were subdivided into clusters of three fruits. The fruits were sprayed with a conidial suspension of $C$. musae at a concentration of $2.5 \times 10^{5}$ conidia $/ \mathrm{mL}$ and were kept in a moist chamber at $25^{\circ} \mathrm{C}$ for 24 hours. After this period, fruits were sprayed with the alternative products 'Biogermex' citric extract, 'Organic Neem' oil and 'Probinatu' garlic oil at a concentration of $10.0 \mathrm{~mL} / \mathrm{L}$, long pepper oil and clove oil, both at a concentration of $5.0 \mathrm{~mL} / \mathrm{L}$, chitosan at a concentration of $10.0 \mathrm{mg} / \mathrm{mL}$, and Tecto ${ }^{\circledR} \mathrm{SC}$ fungicide (thiabendazole) at a concentration of $0.65 \mathrm{~mL} / \mathrm{L}$. Distilled water was used as a control treatment. The fruits treated with chitosan, neem oil and garlic oil had their disease severity reduced. The garlic oil was the most efficient, and had also its disease incidence reduced. The fruit quality was not depreciated by any of the alternative treatments at the concentrations used.
\end{abstract}

Index terms: Postharvest quality, Colletotrichum musae, pathogenic fungi, plant oil and extract.

\footnotetext{
${ }^{1}$ (Trabalho 091-12). Recebido: 08-02-2012. Aceito para publicação: 14-12-2012.

2Eng. Agr., M.Sc., Extensionista Rural Epagri - Empresa Agropecuária e Extensão Rural de Santa Catarina S.A., CEP: 89275-000, Schroeder-SC. E-mail: ricardo@epagri.sc.gov.br

${ }^{3}$ Eng. Agr., Dr., Prof. UFV. Departamento de Fitotecnia, CEP: 36570-000, Viçosa-MG. Pesquisador do CNPq. E-mail: 1salomao@ufv.br ${ }^{4}$ Eng. Agr. Dr., Prof. UFV. Departamento de Fitopatologia, CEP: 36570-000, Viçosa-MG. E-mail: oliparini@ufv.br

${ }^{5}$ Eng. Agr. Dr., Prof. UFV. Departamento de Informática, CEP: 36570-000, Viçosa-MG. Pesquisador do CNPq. E-mail: cecon@dpi.ufv.br

${ }^{6}$ Eng. Agr. Dr., Prof. UFV. Departamento de Fitotecnia, CEP: 36570-000, Viçosa-MG. Pesquisador do CNPq. E-mail: siqueira@ufv.br
} 


\section{INTRODUÇÃO}

São crescentes as exigências do mercado consumidor por frutas de alta qualidade e produzidas com a substituição de insumos poluentes e não renováveis. A necessidade do desenvolvimento de tecnologias alternativas para o controle de doenças em pós-colheita, em substituição aos fungicidas tradicionais, deve-se à demanda da sociedade para a redução do uso de agrotóxicos e à seleção de fitopatógenos resistentes aos compostos químicos sintéticos. A antracnose é uma das principais doenças pós-colheita em banana e manifesta-se principalmente na fruta já madura, levando a perdas significativas. Entre as estratégias sustentáveis no controle de doenças pós-colheita, a indução de resistência e a ação fungistática promovidas por produtos alternativos devem ser consideradas. Os mecanismos de resistência das plantas a doenças podem ser classificados como sendo de origem passiva ou ativa. Os passivos são atributos preexistentes na planta, relativos à estrutura ou à fisiologia, independentemente da presença do patógeno. Os ativos são acionados na forma de reação de defesa do hospedeiro em resposta à infecção, sendo estimulados pela presença do patógeno. A presença de vários componentes na composição de extratos e óleos vegetais pode atuar de forma sinergética e apresentar ampla ação fungicida ou fungistática, como foi evidenciado em testes in vitro (BENKEBLIA, 2004; MEDICE et al., 2007). Além dos óleos e essências vegetais, tem-se a quitosana, que possui propriedades fungicidas contra uma gama de patógenos pós-colheita de frutas e hortaliças. Este trabalho teve como objetivo avaliar produtos alternativos aos agrotóxicos convencionais no controle da antracnose, em pós-colheita de bananas da cultivar 'Prata' [Musa spp. (AAB)].

\section{MATERIAL E MÉTODOS}

Os frutos foram colhidos de pomar comercial em Viçosa-MG, no estádio pré-climatério, com coloração de casca 1 (casca totalmente verde), segundo a escala de cores com valores que variam de 1 a 7 . As pencas centrais dos cachos, com diâmetro médio dos frutos de $32 \mathrm{~mm}$ a $36 \mathrm{~mm}$, foram selecionadas e subdivididas em buquês de três frutos. Estes foram lavados em água potável com $2,0 \mathrm{~mL} / \mathrm{L}$ de detergente neutro para a retirada do látex e desinfestados em solução aquosa de DIPROL I-932 (dicloroisocianurato de sódio - $2,7 \%$ de cloro ativo) $7,4 \mathrm{mg} / \mathrm{mL}$, em imersão por $10 \mathrm{~min}$. Os buquês foram acondicionados em caixas plásticas desinfestadas. Após 24 horas, os frutos foram inoculados com o fungo Colletotri- chum musae. A cultura foi proveniente de coleção do Laboratório de Patologia de Sementes e de Pós-Colheita do Departamento de Fitopatologia da UFV, e a inoculação foi realizada através da pulverização da suspensão de conídios na concentração de $2,5 \times$ $10^{5}$ conídios $/ \mathrm{mL}$, com o uso de pulverizador manual. Os frutos inoculados foram mantidos em câmara úmida a $25^{\circ} \mathrm{C}$ e UR controlada no nível de saturação, por 24 horas. Após, os buquês de frutos inoculados receberam, via pulverização com pulverizador manual, os tratamentos com as caldas dos produtos alternativos extrato cítrico 'Biogermex' $(10,0 \mathrm{~mL} / \mathrm{L})$; óleo de nim 'Organic Neem' (10,0 mL/L); óleo de alho 'Probinatu' $(10,0 \mathrm{~mL} / \mathrm{L})$; quitosana $(10,0 \mathrm{mg} /$ $\mathrm{mL})$; óleo de pimenta-longa $(5,0 \mathrm{~mL} / \mathrm{L})$; óleo de cravo-da-índia $(5,0 \mathrm{~mL} / \mathrm{L})$, fungicida Tecto ${ }^{\circledR} \mathrm{SC}$ (tiabendazol) $(0,65 \mathrm{~mL} / \mathrm{L})$, e água destilada como testemunha. O fungicida Tecto ${ }^{\circledR}$ SC (tiabendazol) foi utilizado como um dos tratamentos por ser um produto-padrão em pós-colheita de bananas.

Todas as caldas foram à base de água e receberam o emulsificante Tween 20 na concentração de $8,0 \mathrm{~mL} / \mathrm{L}$, para a melhor dissolução dos óleos. $\mathrm{O}$ tratamento com quitosana teve também o $\mathrm{pH}$ da calda ajustado para 4,3 , pelo mesmo motivo. Com os frutos secos, após a pulverização das caldas, as almofadas dos buquês (base dos frutos) receberam isolamento feito com biofilme de fécula de mandioca na concentração de $30,0 \mathrm{mg} / \mathrm{mL}$, para evitar a desidratação excessiva (DAMASCENO et al., 2003; SCANAVACA JÚNIOR et al., 2007). Os buquês foram mantidos em câmara climatizada com temperatura de $21 \pm 1{ }^{\circ} \mathrm{C}$ e $80-90 \%$ UR, e as avaliações foram feitas a cada dois dias, a partir do segundo dia após os tratamentos. O experimento foi organizado em esquema de parcelas subdivididas, no delineamento inteiramente casualizado. Utilizaram-se cinco repetições por tratamento, sendo cada unidade experimental constituída por um buquê de três frutos aderidos. Os dados foram submetidos às análises de variância e regressão. As médias das características avaliadas em cada dia foram comparadas pelo teste de Duncan, a $5 \%$ de probabilidade. Para os testes de médias em cada dia de amostragem, foi feito o desdobramento das interações das variáveis avaliadas. A variável produção de $\mathrm{CO}_{2}$ teve apenas análise descritiva dos resultados. Os dados foram analisados com o auxílio do Sistema de Análises Estatísticas e Genéticas da Universidade Federal de Viçosa.

Foram avaliados: Incidência da doença - representa a percentagem de frutos com sintomas da doença. A determinação foi feita com base na fórmula: $\mathrm{I}=$ (NFL/NTF) x 100, em que I = incidência (\%); NFL = número de frutos com lesões; e NFT $=$ número 
total de frutos. Severidade da doença - representa a percentagem da área da casca dos frutos com sintomas da doença. Determinou-se com base em escala diagramática específica para antracnose em bananas, variando de $0 \%$ a $64 \%$ de área lesionada/ fruto. Cor da casca dos frutos - determinou-se na parte mediana do fruto com uso de colorímetro Konica Minolta modelo CR-10, que indica valores de ângulo Hue $\left(\mathrm{h}^{\circ}\right)$, que é a representação do espectro em uma esfera sólida de cores e assume valor zero para a cor vermelha, $90^{\circ}$ para amarela, $180^{\circ}$ para verde e $270^{\circ}$ para azul. Também foi utilizada escala visual de cores com valores que variam de 1 a $7, \mathrm{em}$ que: 1- Fruto totalmente verde; 2- Fruto verde com traços de cor amarela; 3- Fruto mais verde do que amarelo; 4- Fruto mais amarelo do que verde; 5Fruto amarelo com extremidades verdes; 6- Fruto totalmente amarelo; e 7- Fruto amarelo com áreas marrons. Perda de massa da matéria fresca - Os frutos foram pesados em balança eletrônica de precisão de $0,1 \mathrm{~g}$. Os resultados foram expressos em percentagem, com base na diferença entre o peso inicial do fruto e aquele obtido em cada período de amostragem. Taxa respiratória - A produção de $\mathrm{CO}_{2}$ foi determinada por cromatografia a gás. Buquês com três frutos foram acondicionados em frascos de vidro herméticos com volume de $3.280 \mathrm{~mL}$. Trinta minutos após, alíquotas de $3,0 \mathrm{~mL}$ de sua atmosfera foram retiradas com uma seringa e injetadas em um cromatógrafo a gás Gow Mac série 550, com detector de condutividade térmica, equipado com coluna de alumínio preenchida com Porapak Q. As condições de trabalho foram: fluxo de $40 \mathrm{~mL}$ por minuto de gás hélio; corrente elétrica de $150 \mathrm{~mA}$; temperaturas da coluna, do detector e do injetor de $50 ; 70$ e $80{ }^{\circ} \mathrm{C}$, respectivamente, e temperatura ambiente de 23 a $25{ }^{\circ} \mathrm{C}$. A quantificação de $\mathrm{CO}_{2}$ foi feita por meio de comparação dos picos produzidos pela amostra, no cromatograma, com os produzidos pela injeção de uma alíquota-padrão composta de 4,99 mol de $\mathrm{CO}_{2}$ por mol de mistura $\mathrm{CO}_{2}+\mathrm{N}_{2}$. Os resultados foram expressos em $\mathrm{mg}$ de $\mathrm{CO}_{2} / \mathrm{kg} / \mathrm{h}$.

\section{RESULTADOS E DISCUSSÃO}

Intensidade da doença - A incidência da doença nos frutos tratados com óleo de alho e óleo de pimenta-longa foi reduzida em $86,67 \%$ e $53,34 \%$, respectivamente, em relação à testemunha água, aos 12 dias após os tratamentos (Tabela 1). Os demais tratamentos não foram eficientes na redução da incidência da doença. A eficiência do tratamento óleo de alho, em retardar o aparecimento da doença, aumentou em quatro dias o tempo de vida de prate- leira dos frutos, em relação ao tratamento com água (Figura 1). Esse é um aspecto favorável à comercialização, pois Matsuura et al. (2004), ao estudarem as preferências do consumidor quanto aos atributos de qualidade dos frutos de bananas, verificaram que o tempo de 7 a 10 dias de vida útil em condições ambientes é o exigido pelo consumidor. A severidade da doença, nos frutos tratados com óleo de alho e tiabendazol, manteve-se abaixo de $2 \%$ até os 16 dias após os tratamentos (Figura 2). Aos 18 dias após os tratamentos, a severidade da doença foi reduzida nos frutos tratados com tiabendazol, quitosana, óleo de nim e óleo de alho em 59,66\%, 50,89\%, 49,39\% e $41,67 \%$, respectivamente, em relação à testemunha água, que apresentou nessa data $44,80 \%$ de severidade da doença (Tabela 1). Os tratamentos com extrato cítrico, óleo de pimenta-longa e óleo de cravo-da-índia não foram eficientes na redução da severidade da doença. Em trabalho realizado por Carré et al. (2006), quitosana na concentração de $0,25 \mathrm{mg} / \mathrm{mL}$, reduziu-se a severidade de antracnose em $63 \% \mathrm{em}$ frutos de banana 'Prata' tratados na pós-colheita, em relação à testemunha. A eficiência na redução da intensidade da antracnose conferida por esses produtos alternativos deve-se ao fato de poderem ter atuado de duas formas: a primeira, pela indução de resistência. A resistência vegetal pode ser melhorada através da produção de metabólitos secundários e mecanismos de defesa estruturais mais eficientes. Isso é possível devido à presença, na composição desses óleos essenciais e da quitosana, de bioflavonoides e polímeros, precursores dos compostos secundários fitoalexinas e quitinases, respectivamente, responsáveis pela defesa vegetal; a segunda, pela ação germicida através da ruptura de membranas celulares dos fungos, como evidenciado em testes realizados in vitro por Benkeblia (2004), que relatou a inibição do crescimento micelial de Aspergillus niger e Penicillium cyclopium com o uso de óleos essenciais de alho e de cebola. Cor da casca dos frutos - O fungicida tiabendazol manteve o índice de cor mais baixo do $4^{\circ}$ ao $18^{\circ}$ dia e ângulo Hue mais alto entre 6 e 15 dias após os tratamentos (Figuras 3 e 4), com os frutos apresentando a coloração da casca mais verde por mais tempo, retardando, dessa forma, o amadurecimento em relação aos demais tratamentos. Essa coloração da casca deve-se ao bom desempenho que esse produto teve na redução da severidade da doença nos frutos. A presença de patógenos antecipa $o$ amadurecimento das bananas (LICHTEMBERG et al., 2008), deixando-as com a cor da casca mais amarela. Perda de Massa da Matéria Fresca - A perda de massa da matéria fresca foi menor nos tratamentos cujos produtos melhor controlaram a intensidade da 
antracnose, como o fungicida tiabendazol $(0,42 \%$ ao dia) e óleo de alho $(0,46 \%$ ao dia) (Figura 5). Com a presença de microrganismos nos tecidos, há estímulo à senescência, aumentando a atividade respiratória $\mathrm{e}$ a difusão de gases e, por consequência, há maiores perdas de massa da matéria fresca dos frutos. Aos 18 dias, última data avaliada, os frutos tratados com tiabendazol, extrato cítrico e óleo de alho diferiram significativamente daqueles tratados com água, quitosana, óleo de nim e óleo de cravo-da-índia (Tabela 2). Produção de $\mathrm{CO}_{2}$ - Com exceção dos frutos tratados com quitosana, o pico climatérico da respiração ocorreu entre 8 e 10 dias após os tratamentos (Figura 6). Após o pico, houve declínio da produção de $\mathrm{CO}_{2}$ (pós-climatérico), retornando a elevar-se após o 14 dia (Figura 6). O aumento da severidade da doença e, consequentemente, da área da casca lesionada, verificada a partir dos 14 dias após os tra- tamentos, elevou a produção de etileno, o que explica a retomada da elevação na produção de $\mathrm{CO}_{2}$ (Figura 6). A respiração do próprio fungo também deve ter contribuído para esse aumento final da produção de $\mathrm{CO}_{2}$. A respiração e a consequente produção de $\mathrm{CO}_{2}$ são potencializadas por infecções devido à presença de microrganismos e pela exposição do tecido vegetal danificado. Os frutos tratados com quitosana tiveram a produção máxima de $\mathrm{CO}_{2}$ antecipada em torno de 3 dias, em relação aos demais produtos. Entretanto, houve redução no valor máximo da taxa respiratória por esse tratamento, em relação aos frutos tratados com água (Figura 6). Mazaro et al. (2008) observaram desempenho semelhante em morangos tratados com quitosana, na concentração de $10,0 \mathrm{mg} / \mathrm{mL}$, quando estudavam o comportamento pós-colheita dessa fruta após a aplicação pré-colheita de quitosana.

TABELA 1 - Incidência e severidade da antracnose em bananas 'Prata', aos 12 e 18 dias após os tratamentos com produtos alternativos ou fungicida, e armazenamento a $21 \pm 1{ }^{\circ} \mathrm{C}$ e $80-90 \%$ UR

\begin{tabular}{|c|c|c|c|c|}
\hline \multirow{3}{*}{ Tratamentos } & \multicolumn{4}{|c|}{ Dias após Tratamentos } \\
\hline & \multicolumn{2}{|c|}{12 Dias } & \multicolumn{2}{|c|}{18 Dias } \\
\hline & Incidência (\%) & Severidade (\%) & Incidência (\%) & Severidade $(\%)$ \\
\hline Água & $100,00 \mathbf{a}$ & $3,20 \mathbf{a}$ & $100,00 \mathbf{a}$ & 44,80 a \\
\hline Tiabendazol & 53,33 abc & $0,27 \mathbf{a}$ & $93,33 \mathbf{a}$ & 18,07 \\
\hline Extrato cítrico & 53,33 abc & $0,30 \mathbf{a}$ & $100,00 \mathbf{a}$ & 27,03 abc \\
\hline Quitosana & 53,33 abc & $1,93 \mathbf{a}$ & $93,33 \mathbf{a}$ & $22,00 \quad$ bc \\
\hline Óleo de nim & $73,33 \mathbf{a b}$ & $1,60 \mathbf{a}$ & $100,00 \mathbf{a}$ & 22,67 bc \\
\hline Óleo de pimenta-longa & 46,66 bc & $1,03 \mathbf{a}$ & $100,00 \mathbf{a}$ & $32,80 \mathbf{a b}$ \\
\hline Óleo de cravo-da-índia & 53,33 abc & $1,43 \mathbf{a}$ & $100,00 \mathbf{a}$ & $35,20 \mathbf{a b}$ \\
\hline Óleo de alho & $13,33 \quad \mathbf{c}$ & $0,10 \mathbf{a}$ & $100,00 \mathbf{a}$ & 26,13 bc \\
\hline
\end{tabular}

Os valores representam médias de cinco repetições.

Médias seguidas por letras diferentes, nas colunas, diferem estatisticamente entre si, pelo teste de Duncan, a 5\% de probabilidade.

TABELA 2 - Perda de massa de matéria fresca (\% de perda) de bananas 'Prata' mantidas a $21 \pm 1{ }^{\circ} \mathrm{C}$ e 80 - 90\% UR, após tratamento com diferentes produtos alternativos ou fungicida

\begin{tabular}{lcc}
\hline \multirow{2}{*}{ Tratamentos } & \multicolumn{2}{c}{ Dias após os Tratamentos } \\
\cline { 2 - 3 } Água & 12 Dias & 18 Dias \\
Tiabendazol & $5,46 \mathbf{a}$ & $12,31 \mathbf{a}$ \\
Extrato cítrico & $4,59 \mathbf{~ a}$ & $9,04 \mathbf{c}$ \\
Quitosana & $5,16 \mathbf{a}$ & $10,51 \mathbf{~ b c}$ \\
Óleo de nim & $6,16 \mathbf{a}$ & $12,23 \mathbf{a}$ \\
Óleo de pimenta-longa & $6,07 \mathbf{a}$ & $12,85 \mathbf{a}$ \\
Óleo de cravo-da-índia & $5,16 \mathbf{a}$ & $11,85 \mathbf{a b}$ \\
Óleo de alho & $5,91 \mathbf{a}$ & $12,13 \mathbf{a}$ \\
\hline
\end{tabular}

Os valores representam médias de cinco repetições.

Médias seguidas por letras diferentes, nas colunas, diferem estatisticamente entre si, pelo teste de Duncan, a 5\% de probabilidade. 


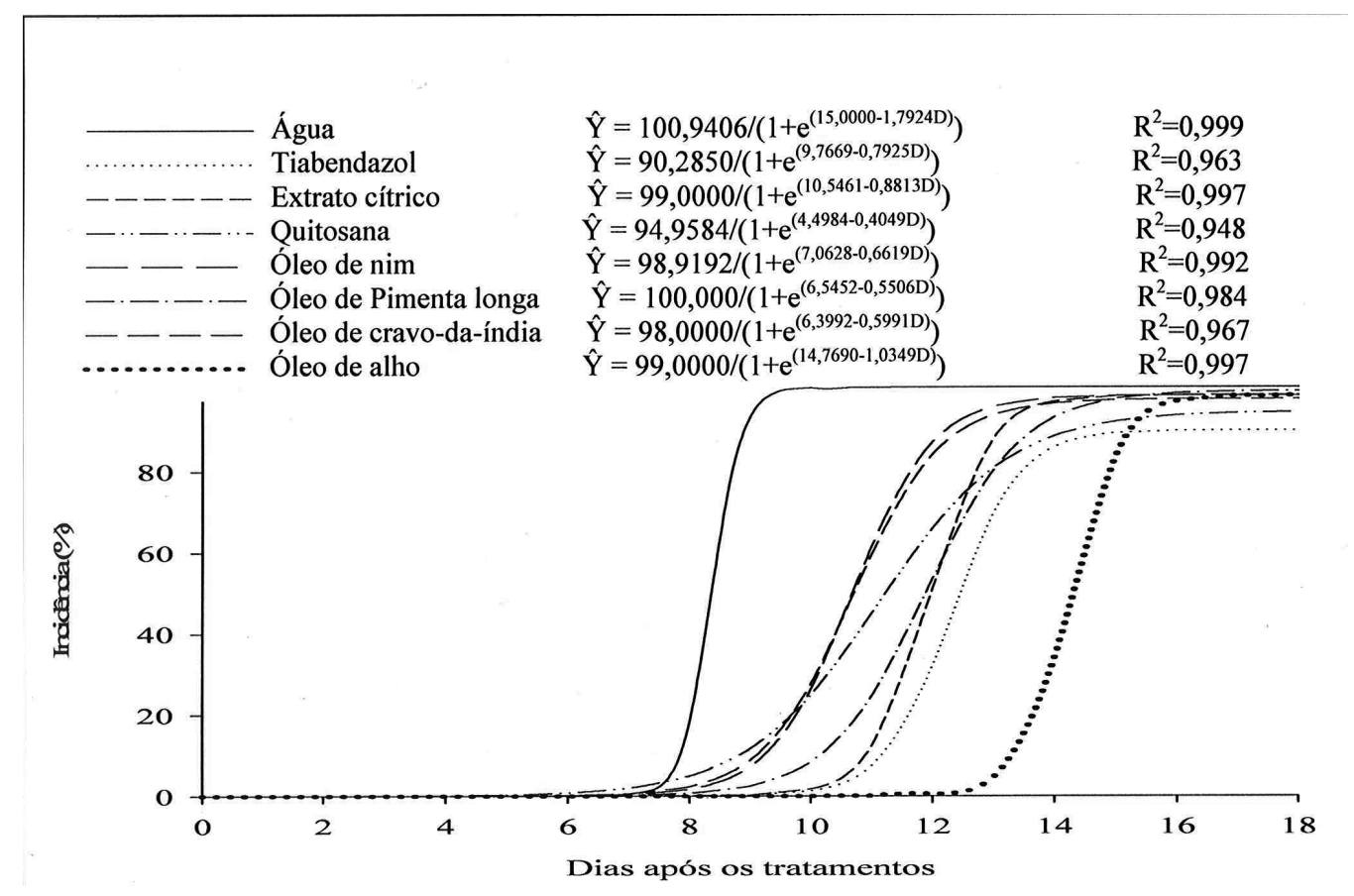

FIGURA 1 - Incidência (\% de frutos com sintomas) de antracnose em bananas 'Prata' mantidas a $21 \pm 1$ ${ }^{\circ} \mathrm{C}$ e $80-90 \%$ UR, em função do tempo após os tratamentos com produtos alternativos ou fungicida. Médias de cinco repetições.
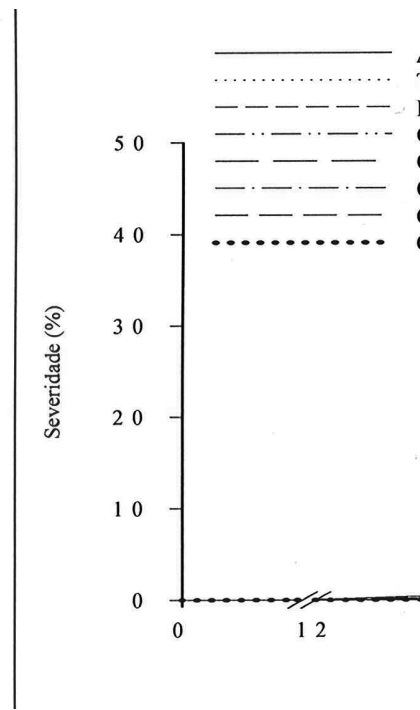

\section{Água \\ Tiabendazol}

Extrato cítrico

Quitosana

Óleo de nim

Óleo de pimenta longa

Óleo de cravo-da-índia

Óleo de alho

$\hat{Y}=90,2850 /\left(1+\mathrm{e}^{(9,7669-0,7925 \mathrm{D})}\right)$
$\hat{\mathrm{Y}}=99,0000 /\left(1+\mathrm{e}^{(10,5461-0,8813 \mathrm{D})}\right)$
$\hat{\mathrm{Y}}=94,9584 /\left(1+\mathrm{e}^{(4,4984-0,4049 \mathrm{D})}\right)$
$\hat{\mathrm{Y}}=98,9192 /\left(1+\mathrm{e}^{(7,0628-0,6619 \mathrm{D})}\right)$
$\hat{\mathrm{Y}}=100,000 /\left(1+\mathrm{e}^{(6,5452-0,5506 \mathrm{D})}\right)$
$\hat{\mathrm{Y}}=98,0000 /\left(1+\mathrm{e}^{(6,3992-0,5991 \mathrm{D})}\right)$
$\hat{\mathrm{Y}}=99,0000 /\left(1+\mathrm{e}^{(14,7690-1,0349 \mathrm{D})}\right)$

$\mathrm{R}^{2}=0,948$

$\mathrm{R}^{2}=0,992$

$\mathrm{R}^{2}=0,984$

Dias após os tratamentos

** Significativo a $1 \%$ de probabilidade, pelo teste " $\mathrm{t}$ "

* Significativo a $5 \%$ de probabilidade, pelo teste " $\mathrm{t}$

FIGURA 2 - Severidade ( $\%$ da área dos frutos com sintomas) de antracnose em bananas 'Prata' mantidas a $21 \pm 1{ }^{\circ} \mathrm{C}$ e $80-90 \%$ UR, em função do tempo após os tratamentos com produtos alternativos ou fungicida. Médias de cinco repetições. 


\begin{tabular}{|c|c|c|c|}
\hline & Água & $\hat{\mathrm{Y}}=0,3283+0,1895 \mathrm{D}+0,0631 \mathrm{D}^{2}-0,0029^{*} \mathrm{D}^{3}$ & $\mathrm{R}^{2}=0,980$ \\
\hline ................. & Tiabendazol & $\hat{\mathrm{Y}}=1,9555-0,6091 * \mathrm{D}+0,1214 * * \mathrm{D}^{2}-0,004 * * \mathrm{D}^{3}$ & $\mathrm{R}^{2}=0,984$ \\
\hline------ & Extrato cítrico & $\hat{\mathrm{Y}}=1,2924-0,3075 \mathrm{D}+0,104 * \mathrm{D}^{2}-0,0038^{* *} \mathrm{D}^{3}$ & $\mathrm{R}^{2}=0,980$ \\
\hline$-\cdots-\cdots-\cdots-$ & Quitosana & $\hat{\mathrm{Y}}=1,0536+0,3716 * * \mathrm{D}$ & $\mathrm{R}^{2}=0,891$ \\
\hline--- & Óleo de nim & $\hat{\mathrm{Y}}=0,5166+0,4216^{* *} \mathrm{D}$ & $\mathrm{R}^{2}=0,878$ \\
\hline$-\cdot---$ & Óleo de pimenta longa & $\hat{\mathrm{Y}}=0,7919+0,4022 * * \mathrm{D}$ & $\mathrm{R}^{2}=0,888$ \\
\hline---- & Óleo de cravo-da-índia & $\hat{Y}=0,8856+0,3942 * * D$ & $\mathrm{R}^{2}=0,916$ \\
\hline n......... & Óleo de alho & $\hat{\mathrm{Y}}=0,9407-0,0964 \mathrm{D}+0,078 * \mathrm{D}^{2}-0,003 * \mathrm{D}^{3}$ & $\mathrm{R}^{2}=0,980$ \\
\hline
\end{tabular}

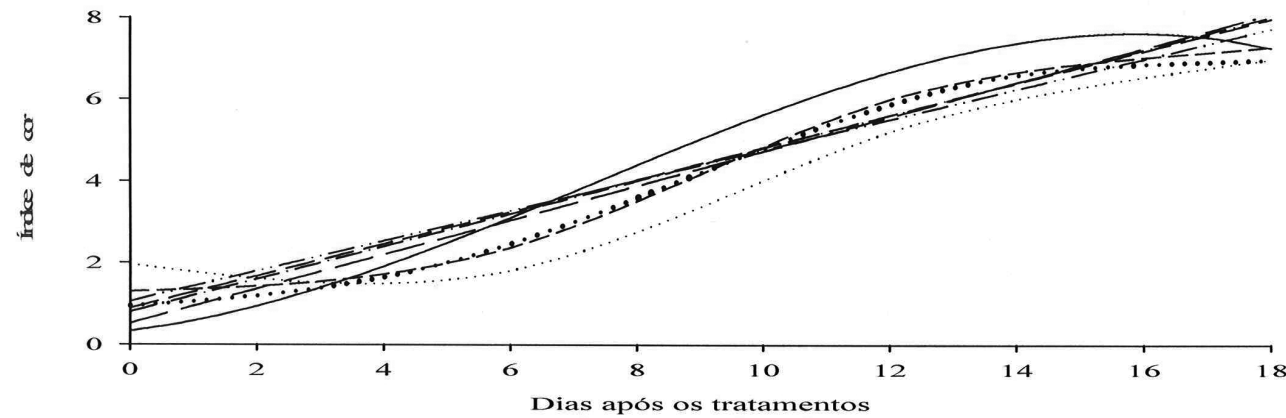

** Significativo a $1 \%$ de probabilidade, pelo teste " $\mathrm{t}$ "

* Significativo a $5 \%$ de probabilidade, pelo teste " $\mathrm{t}$ "

FIGURA 3 - Cor da casca (médias dos índices de cores definidos por Dadzie e Orchard, 1997) de bananas 'Prata' mantidas a $21 \pm 1{ }^{\circ} \mathrm{C}$ e $80-90 \%$ UR, em função do tempo após os tratamentos com produtos alternativos ou fungicida. Médias de cinco repetições.

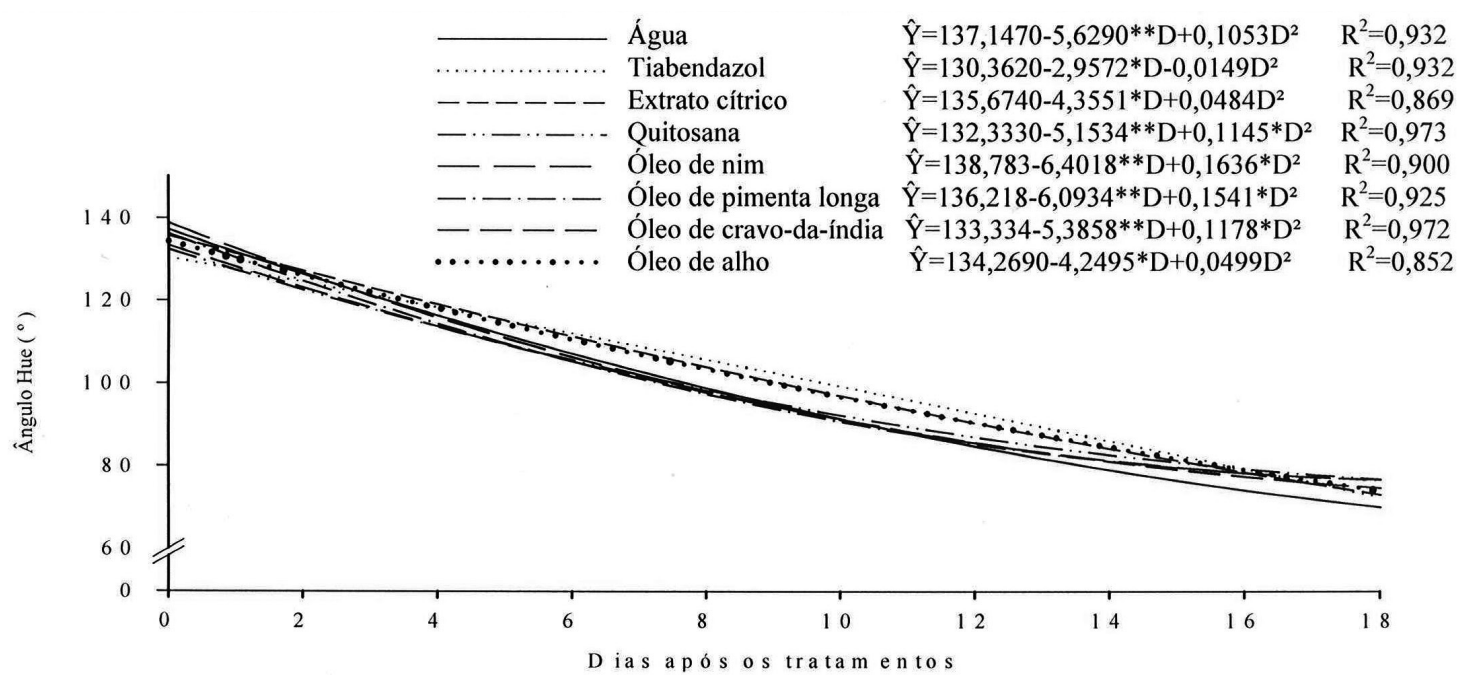

** Significativo a $1 \%$ de probabilidade, pelo teste " $\mathrm{t}$ ".

FIGURA 4 - Ângulo Hue da casca de bananas 'Prata' mantidas a $21 \pm 1{ }^{\circ} \mathrm{C}$ e 80 - 90\% UR, em função do tempo após os tratamentos com produtos alternativos ou fungicida. Médias de cinco repetições. 


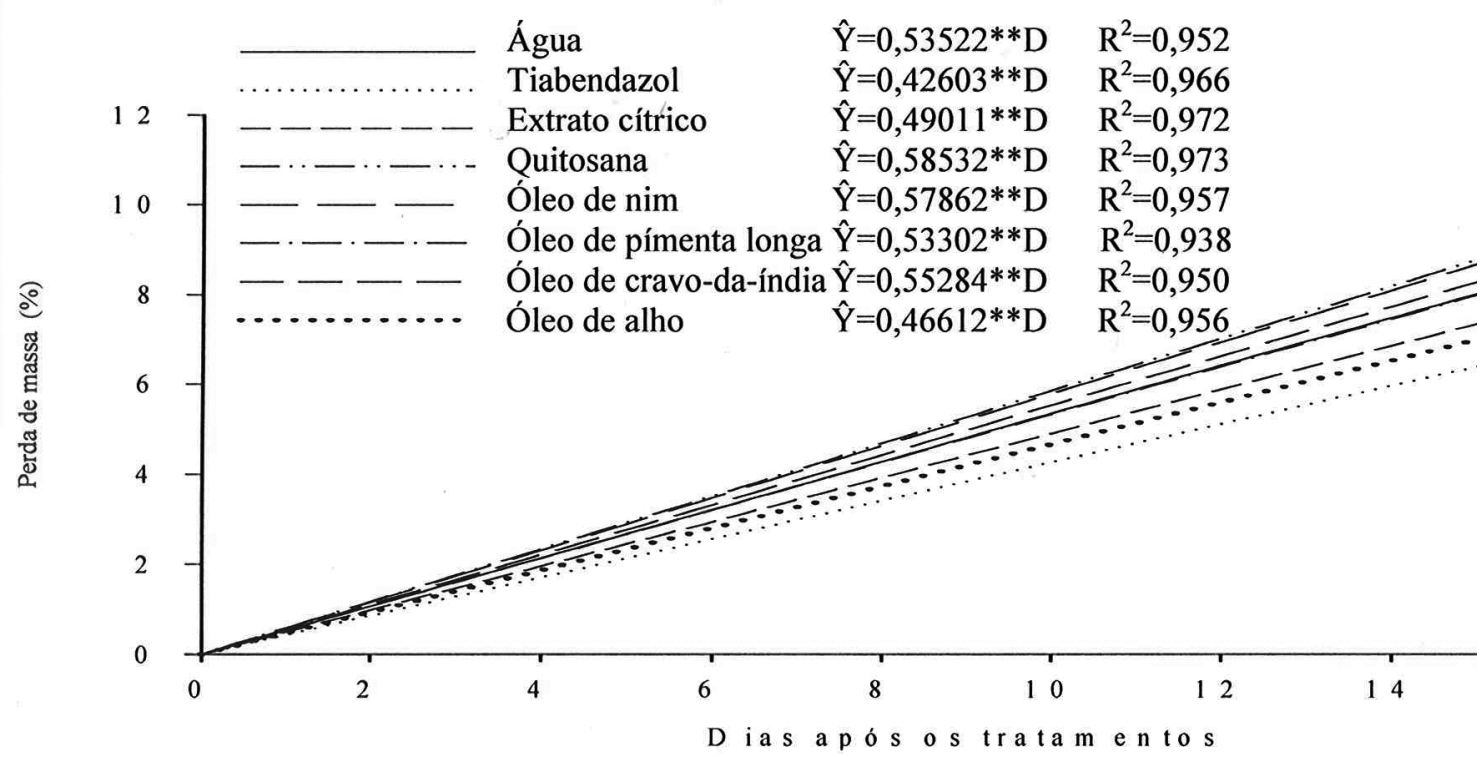

FIGURA 5 - Perda de massa da matéria fresca de bananas 'Prata' mantidas a $21 \pm$ $1{ }^{\circ} \mathrm{C}$ e $80-90 \%$ UR, em função do tempo após o tratamento com produtos alternativos ou fungicida. Médias de cinco repetições.

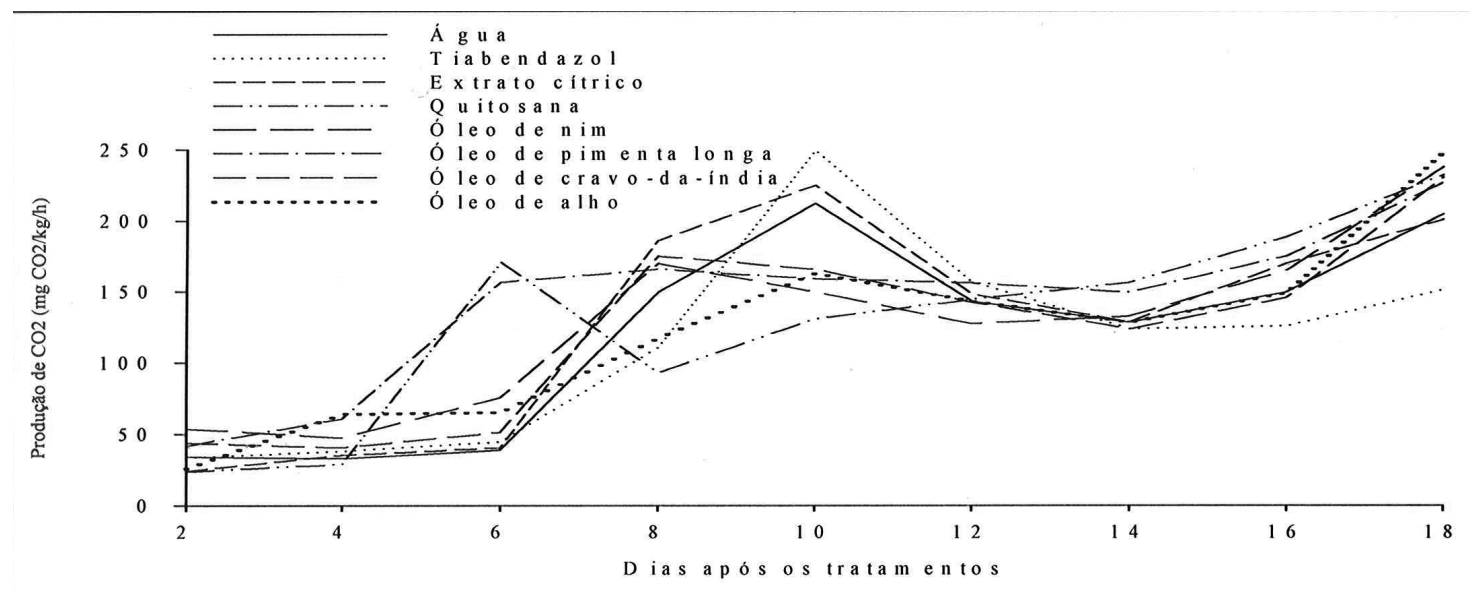

FIGURA 6 - Taxa respiratória $\left(\mathrm{mg} \mathrm{CO}_{2} / \mathrm{kg} / \mathrm{h}\right)$ de bananas 'Prata' mantidas a $21 \pm 1{ }^{\circ} \mathrm{C}$ e $80-90 \% \mathrm{UR}$, em função do tempo após o tratamento com produtos alternativos ou fungicida. 


\section{CONCLUSÕES}

1-Os produtos alternativos óleo de nim e óleo de alho a $10 \mathrm{~mL} / \mathrm{L}$ e quitosana a $10,0 \mathrm{mg} / \mathrm{mL}$ reduziram a intensidade da doença e podem ser recomendados para uso em pós-colheita de bananas 'Prata' no controle da antracnose. Óleo de alho é o mais eficiente, reduz a severidade da doença até 16 dias após o tratamento, igualando-se ao fungicida tiabendazol.

2-A qualidade dos frutos não foi depreciada por nenhum dos tratamentos alternativos nas doses utilizadas.

\section{REFERÊNCIAS}

BENKEBLIA, N. Antimicrobial activity of essential oil extracts of various onions (Allium cepa) and garlic (Allium sativum). Food Science and Technology, Chichester, v. 37, n. 2, p. 263-268, 2004.

CARRÉ, V.; STANGARLIN, J. R.; BECKER, A.; ZANELLA, A. L.; GONÇALVES JR., A. C.; SCHWAN-ESTRADA, K. R. F.; FRANZENER, G.; CRUZ, M. E. S. Controle pós-colheita de Colletotrichum musae em banana (Musa sp.) por cânfora ( $A r$ temisia camphorata) e quitosana. Scientia Agraria Paranaensis, Cascavel, v. 5, n. 1, p. 57-66, 2006.

DAMASCENO, S.; OLIVEIRA, P. V. S.; MORO, E.; MACEDO JR., E. K.; LOPES, M. C.; VICENTINI, N. M. Efeito da aplicação de películas de fécula de mandioca na conservação pós-colheita de tomate. Ciência e Tecnologia de Alimentos, Campinas, v. 23, n. 3, p. 377-380, 2003.
LICHTEMBERG, L. A.; VILAS BOAS, E. V. B.; DIAS, M. S. C. Colheita e pós-colheita da banana. Informe Agropecuário, Belo Horizonte, v. 29, n. 245, p. 85-102, 2008.

MATSUURA, F. C. A. U.; COSTA, J. P. C.; FOLEGATTI, M. S. Marketing de banana: preferências do consumidor quanto aos atributos de qualidade dos frutos. Revista Brasileira de Fruticultura, Jaboticabal, v. 26, n. 1, p. 48-52, 2004.

MAZARO, S. M.; DESCHAMPS, C.; MIO, L. L. M.; BIASI, L. A.; GOUVEA, A.; SAUTTER, C. K. Comportamento pós-colheita de frutos de morangueiro após aplicação pré-colheita de quitosana e acilbenzolar-s-metil. Revista Brasileira de Fruticultura, Jaboticabal, v. 30, n. 1, p. 185-190, 2008.

MEDICE, R.; ALVES, E.; ASSIS, R. T.; JÚNIOR, R. G. M.; LOPES, E. A. G. L. Óleos essenciais no controle da ferrugem asiática da soja (Phakopsora pachyrhizi Syd. \& P. Syd.). Ciência e Agrotecnologia, Lavras, v. 31, n. 1, p. 83-90, 2007.

SCANAVACA JÚNIOR, L.; FONSECA, N.; PEREIRA, M. E. C. Uso de fécula de mandioca na pós-colheita de manga 'Surpresa'. Revista Brasileira de Fruticultura, Jaboticabal, v. 29, n. 1, p. 67-71, 2007. 